\title{
Research on the Construction of Applied Curriculum System in Universities with Transformation and Development
}

\author{
Xi'an Peihua University, Xi'an 710125, China \\ "Corresponding author. Email: zhangwei@ peihua.edu.cn
}

Wei Zhang, ${ }^{1, *}$

\begin{abstract} model.

\section{Background}

Curriculum and curriculum system reform is the core content of the transformation and development of teaching work in application-oriented undergraduate colleges. The traditional curriculum system structure is constructed according to the subject knowledge system, focusing on the classification, induction and storage of knowledge, which is more suitable for thick foundation research cultivation of talents, and for the cultivation of applied talents, a curriculum system based on "knowledge application" is urgently needed. At present, the curriculum system with knowledge reserve as the main feature can no longer meet the needs of talent development for transformation and development. For transformation colleges and universities, there is an urgent need for a project-oriented, systemoriented work process as the guiding ideology, and knowledge application as the leading Instructional model of applied talent training curriculum system.
\end{abstract}

Abstract. Curriculum system reform is the core content of the transformation and development of teaching work in application-oriented undergraduate colleges. For transformation colleges and universities, there is an urgent need for a project-oriented, systematized work process as the guiding ideology, and knowledge application as the guiding model of the application-oriented talent training course system. The main content of the research of this topic is to design a curriculum system for the application of technical professionals based on the educational concept of OBE achievement-oriented education. It is based on job requirements and professional ability training, and establishes the requirements of knowledge, ability, quality and curriculum system according to the training objectives. Mapping matrix, focuses on studying the internal logical relationship between course contents in the course system, and designs a "point-line-face-body-net" course system for application-oriented talent training based on the "work process systemization" course development method

Keywords: transformation and development; applied curriculum; curriculum system.

\section{Research Content}

The main content of the research of this topic is to design a curriculum system for the application of technical professionals based on the educational concept of OBE achievement-oriented education. It is based on job requirements and professional ability training, and establishes the requirements of knowledge, ability, quality and curriculum system according to the training objectives.
Mapping matrix, and focus on studying the internal logical relationship between course content in the course system, and designing a "point-line-face-body-net" course system for application-oriented talent training based on the "work process systemization" [1] course development method model. Taking the typical majors of different majors such as computer science and technology, architecture, international trade as samples, we sorted out the curriculum groups of each professional talent training and the job group, and established the content connection and technical support relationship between the courses. And the induction method of knowledge points and skill points included in the course unit, so as to improve the effectiveness and goal achievement of the training of applied talents, and make this program have certain reproducibility and promotion, making it an application A model sample of the construction of curriculum system and curriculum reform in large universities.

\subsection{Research objectives}

The research goal of this topic is based on the OBE achievement-oriented education concept, in accordance with the "reverse design, forward implementation" method, according to the application of talent training goals to design the graduation requirements, graduation requirements index points, curriculum objectives, curriculum structure, curriculum The basic ideas of content (learning scenarios with real projects as carriers), knowledge points (basic concepts and basic theories) and skill points (general skills and professional skills). Then, related and integrated 
teaching content related to the support of a certain index point (knowledge, ability, quality), and the project leader has a certain research basis of the "point-line-surface-body" course structure model, continue to improve, based on the principle of achievement-oriented, according to the curriculum teaching goals to achieve the graduation requirements index points, to achieve an organic connection between the course units, so as to build the knowledge points and skill points of classroom teaching It is a "point", taking the working steps in the actual work as the "line", taking the task or learning situation designed and developed by the teacher as the "face", and taking a single course as the course unit as the "body", and taking the entire professional course system It is a "point-line-area-body-net" course system model of "net" for application-oriented majors.

\subsection{The main problem to be solved}

This subject mainly solves structural design problems such as the existence of relatively independent knowledge modules in the curriculum system of the professional talent training program based on the traditional subject knowledge system, ambiguous training objectives, unclear output of results, and difficulty in landing practical ability. [2]

This subject carries out further research based on the previous research model, which can solve the problem of achieving the organic connection of knowledge points and skill points in different course units, so that the course units are no longer relatively independent, and the course content and work Process docking, curriculum group and job group docking, so as to form a complete, organic curriculum model for application-oriented talent training.

\subsection{Innovation}

Proposed and designed a "point-line-area-body-net" curriculum system model based on the cultivation of applied talents, making up for the gaps in the concept design and theoretical research of top-level design in the field of applied curriculum reform;

Based on the OBE results-oriented, sort out the knowledge points and skill points related to the course teaching content according to the logical relationship between the training goals-graduation requirements-graduation requirements index points-course teaching goals-knowledge ability quality[3], and then integrates the implementation steps of these knowledge points and skill points based on the design of workflow, learning situation, and the integration of curriculum unit Combine organically to provide support and basis for the realization of curriculum objectives and talent training objectives. [4]The design method is not only logical, but also easy to understand and implement, and can provide effective ideas and practical methods for the construction of an application-oriented curriculum system.

\subsection{Promotion value}

This topic will address two important issues in the design of the curriculum system (relationship between curriculum and curriculum) and curriculum structure (relationship between content and content), opening up the relationship between curriculum group and curriculum content from top-level design to teaching implementation Logic. Based on the OBE concept and the "systematization of work processes" method, the application-oriented undergraduate professional curriculum system is designed and developed. The original "point-line-surface-body-net" curriculum system reference model that can reflect the characteristics of engineering practice and application can solve the application of colleges and universities. The core and fundamental issues concerning the deconstruction and reconstruction of the curriculum system in the teaching of technology transformation.

The relevant research results expected from this topic can be used as one of the reference basis for providing professional talent training program revision and curriculum system construction for more than 600 transformation and development universities across the country, and provide program design ideas and reference samples for the application-oriented curriculum reform in related universities.

\section{Research Methods}

The development of the curriculum system based on the work process is a teaching model oriented by the work process. The job groups targeted by the major are analyzed through market research, and then the job tasks are analyzed for the job groups to extract the typical work tasks and then the typical Analyze the work tasks, divide the action areas according to the career development laws and the difficulty of the work tasks, and according to the professional abilities (professional ability, method ability and social ability) required for typical work tasks, the action areas are correspondingly converted into learning areas , Build a professional course system based on work process, analyze the knowledge and skills involved in the field of study, introduce real or simulated work process situation to organize teaching, formulate a teaching evaluation system based on the standard of enterprise work task completion, and allow students to obtain real career positions or job group occupations A course teaching system with competence requirements.

Curriculum system development is to systematically express the specific work process in a form that is convenient for organizing and implementing teaching, and show it through specific learning situations, then organize the teaching in the form of teaching units, and then integrate the different course units, and Realize the organic connection of knowledge points and skill points between course units, and finally constitute the "point-line-surfacebody-net" application-oriented course system model. 


\section{Conclusion}

Based on the OBE achievement-oriented concept, this article sorts out the relevant knowledge points and skill points of the course teaching content according to the logical relationship between the training goals-graduation requirements-graduation requirements index points-course teaching goals-knowledge ability quality, and then these knowledge points and skill points The integration of the implementation steps based on the working process, the design of the learning situation, and the integration of the course units are organically integrated to provide support and basis for the achievement of the course goals and talent training goals. The design idea of this topic research is based on the traditional OBE talent training program, and the course structure, content, implementation and other links are subdivided and designed, so that the advanced concept of $\mathrm{OBE}$ is more systematic and operational in the application of college. This design method is not only logical, but also easy to understand and implement. It can provide effective ideas and practical methods for the construction of an application-oriented curriculum system.

\section{ACKNOWLEDGMENT}

This research was financially supported by the Shaanxi Higher Education Teaching Reform Research Project (Research and Practice on the Construction of Applied Curriculum System in Universities with Transformation and Development, 2019.12-2021.6, project number 19BG034, Shaanxi Provincial Department of Education).

\section{REFERENCES}

[1] Jiang Dayuan. On the Systematic Design of Higher Vocational Education Curriculum- Interpretation of Systematic Curriculum Development of Work Process[J]. China Higher Education Research, 2009, (04): 66-70.

[2] Jiang Dayuan. Structural problems are the key to curriculum development [N]. China Education News, 2016-08-23 (003).

[3] Zhang Yongding, Ma Lisheng, Wen Weimin, Yao Guangshun. Exploration of talent training programs for local applied universities under the background of engineering education certification [J]. Journal of Heilongjiang Institute of Technology, 2020, 34 (02): 6972.
[4] Liang Xiaohong, Wu Ronghua. Course Construction Path and Teaching Quality Assurance of Newly Applied Undergraduate Universities [J]. Journal of Chongqing University of Science and Technology (Social Science Edition), 2020 (02): 110-113.

[5] Gao Guoqiang, Yu Lihui, Zhao Lu. Research on the establishment of the course system of tea science in local applied undergraduate colleges [J]. Chinese Journal of Multimedia and Network Education (Last Issue), 2020 (03): 203-204 